\title{
A SENSIBILIDADE SECULAR DA POLÍTICA BRASILEIRA
}

\author{
Eduardo Dullo ${ }^{1}$ \\ Rafael Quintanilha ${ }^{2}$
}

\begin{abstract}
Resumo: A religião vem se consolidando como um tema de controvérsia e manifestação nas eleiçōes brasileiras das últimas décadas. Apesar disso, os pesquisadores têm se mantido restritos aos agentes religiosos, ignorando a sua contraparte relacional, isto é, os agentes que questionam ou rejeitam a presença religiosa na política eleitoral. Este artigo pretende discutir as críticas feitas ao pertencimento religioso da candidata Marina Silva, sobretudo pela via do humor, como uma maneira de acesso à sensibilidade secular da política brasileira contemporânea. Uma das conclusões é a de que o conflito entre distintas comunidades morais pode ser melhor compreendido por meio do conceito de cismogênese, proposto por Bateson, e que esse conflito mantém ativa a tensão dinâmica entre o religioso e o secular.
\end{abstract}

Palavras-chave: Religião; Política; Secularismo; Humor; Eleição.

Abstract: Religion is increasingly becoming a subject of controversy and mobilization in the Brazilian political disputes of the last decades. Despite this fact, researchers had kept the focus at the religious agents, thus ignoring their relational counterpart those who question or reject the religious presence in party politics. This text aims to discuss the criticism made, mainly via humour, to Marina Silva's religious affiliation as a way to access the secular sensibility of contemporary Brazilian politics. One of our conclusions is that the conflict between two distinct moral communities can be better understood via Bateson's concept of schismogenesis and that this conflict maintains the dynamic tension between the religious and the secular active.

Keywords: Religion; Politics; Secularism; Humour; Election.

1 Doutor em Antropologia Social pelo Museu Nacional/UFRJ; Pós-doutorado - Departamento de Antropologia/USP e Pesquisador Associado do CEBRAP. Atualmente (2015-2016), Visiting Scholar no Depto. de Antropologia da Universidade de Cambridge. Contato: edudullo@gmail.com

2 Bacharel em Ciências Sociais/USP e Pesquisador Associado do CEBRAP. Contato: qrafael@gmail.com

Debates do NER, Porto Alegre, Ano I6, N. 27, P. I73-I98, JAn./Jun. 2015 


\section{INTRODUÇÃO}

Nas campanhas eleitorais de 2014 para a presidência da República, assistimos mais uma vez a calorosas discussões, entre e sobre candidatos, que envolviam o tema da religião. $\mathrm{O}$ assunto dificilmente pode ser chamado de novidade ou de pouco usual. Nos últimos pleitos, tanto em nível federal quanto nos níveis estaduais e municipais, o tema da religião tem se feito cada vez mais presente. Apesar disso, as pesquisas acadêmicas a respeito do assunto restringiram-se, majoritariamente, a alguns poucos aspectos. Centralmente, pode-se notar que o tema mais discutido é o pertencimento religioso cristão de candidatos e políticos eleitos, resumida na expressão "bancada evangélica" . Seria ingenuidade pensar, no entanto, que tal presença religiosa não promove uma reação secular ou ainda que essa reação não é parte do próprio fenômeno em questão. A proposta deste artigo é dar início a essa discussão e promover uma hipótese inicial da sensibilidade secular da política eleitoral brasileira.

Porém, como já enfatizaram Talal Asad (2003) e Charles Hirschkind (2011), uma antropologia do secularismo (Dullo, 2012) dificilmente pode ser bem sucedida quando enfrentamos o assunto diretamente. Certos subterfúgios ou, melhor dizendo, deslocamentos de perspectiva, são necessários para que possamos descrever a "sensibilidade secular".

Um argumento que orienta a construção de uma possível antropologia do secularismo coloca em questão a maneira de conhecer e de pesquisar algo

3 Os artigos referem-se, sobretudo, ao pertencimento religioso de candidatos e políticos eleitos (Oro; Mariano, 2010; Tadvald, 2010), a relação entre os fiéis de certas igrejas e os candidatos vinculados de alguma maneira a essas denominaçôes (por exemplo, Meirelles; Weege; Picolloto, 2010) e às discussões sobre propostas legislativas que são sustentadas por morais e crenças religiosas (Luna, 2014; Sales, 2014). São raros os textos sobre religiosos não cristãos presentes na política (sobre religiōes de matriz africana, ver Bem; Leistner, 2010; Otero; Ávila; Shoenfelder, 2004). Infelizmente, não conhecemos análises comparativas da bancada evangélica e de outras bancadas, permitindo, assim, compreender em que medida o pertencimento religioso é um diferencial na atuação parlamentar.

Debates do NER, Porto Alegre, Ano i6, N. 27, P. I73-I98, JAN./Jun. 2015 
no qual estamos plenamente imersos, já que se trata de uma ciência secular tentando analisar a secularidade. Para nós, esta é a problemática não apenas de se pesquisar at home, mas, sobretudo, do limite de uma "autoantropologia" nos termos de Marilyn Strathern (1987). Ao considerar que vivemos numa era secular (Taylor, 2007) e ao concordarmos que essa é uma das condições de possibilidade para a formação da própria ciência social que praticamos, estamos situados exatamente naquele limite da autoantropologia: a forma de conhecimento utilizada pelo pesquisador é oriunda daquilo que ele pretende analisar.

Por essa razão, nossa proposta é observar o uso de um tipo específico de discurso, o humor, para promover essa perspectiva deslocada. Ao trabalhar com o discurso político humorístico, apoiamo-nos nas propostas de Mary Douglas (1975) e de Simon Critchley (2002), segundo as quais o humor permite ao pesquisador compreender os sentidos implícitos compartilhados por uma determinada comunidade moral, bem como o desenvolvimento recente proposto por Hans Steinmüller (2011) sobre a ironia (entendida aqui como uma possível forma de humor) como formadora de comunidades morais.

Yael Navaro-Yashin (2002) apresenta uma etnografia da vida pública na Turquia no momento imediatamente anterior e posterior às eleiçōes de 1994, em que representantes políticos muçulmanos voltaram ao poder após décadas de um estrito regime secular. Sua monografia é inspiradora na medida em que a autora trabalha com o humor (nervoso) proveniente da tensão, evidenciando as expectativas de uma classe média secular educada, desenvolvendo ainda análises sobre a ironia e o cinismo como parte da vida política cotidiana.

Mas retornemos ao que estamos entendendo por humor. Critchley (2002, p. 2-3) apresenta três teorias amplas e consolidadas ao longo dos séculos, a teoria da superioridade, a do alívio e a da incongruidade. Embora seja possível observar nos fenômenos concretos aspectos das três (como se fossem tipos ideais), ele opta por desenvolver seu trabalho centralmente a partir da última. Para isso, ele se apoia no texto de Douglas, no qual ela afirma:

Debates do NER, Porto Alegre, Ano I6, N. 27, P. I73-I98, JAn./Jun. 2015 
Uma piada é um jogo com os formatos. Ela coloca em relação elementos díspares de maneira que um padrão aceito é desafiado pelo aparecimento de outro padrão, que estava oculto no primeiro de alguma maneira. [...] Desnecessário dizer que uma subversão bem-sucedida de um formato por outro completa ou termina a piada, pois isso muda a balança de poder $(1975 \text {, p. } 96)^{4}$.

Assim, Critchley considera que o humor e a piada jogam justamente com as formas e as práticas de uma determinada sociedade, muitas vezes com aspectos implícitos, o que faz com que o "[...] humor seja produzido por uma disjunção entre o modo como as coisas são e o modo como elas são representadas na piada, entre expectativa e atualidade" (2002, p. 1). Ao fazer isso, o humor "[...] nos permite ver o familiar como estranho, o ordinário como extraordinário e o real como surreal, e então nós rimos [...]" (2002, p. 10). É esse aspecto de disjunção entre um padrão esperado e um padrão realizado que nos parece mais relevante de manter das possíveis delimitações do humor. É justamente ao promover a disjunção e explicitar padrões implícitos que o humor nos fornece um deslocamento de perspectiva para abordar o secular.

Mas, além disso, esse jogo com as formas pode ser encontrado de uma maneira mais ampla na discussão sobre a ironia, ao considerarmo-na, como sugere Safatle (2008, p. 28), um dos "atos de fala de duplo nível”" Nesses casos, há uma "distorção performativa”, o que também pode ser remetido à mesma teoria da incongruência, que nos permite recompor a noção de compartilhamento em comunidades morais: "[...] o riso irônico funda e fornece as coordenadas do espaço comum destes que partilham olhares que dizem tudo que as palavras não afirmam" (2008, p. 32, grifo do autor).

4 Todas as citações traduzidas são de responsabilidade dos autores.

5 Safatle categoriza seis tipos desses atos de fala: a má-fé, a hipocrisia, a metáfora, as indiretas, a ironia e o cinismo. Para a discussão aqui em pauta, é relevante a diferença entre as duas primeiras em que "a exposição da clivagem anula a força perlocucionária do ato" e as duas últimas em que o sucesso depende justamente do reconhecimento ou da revelação da inadequação.

Debates do NER, Porto Alegre, ANo I6, N. 27, P. I73-I98, JAN./Jun. 2015 
Hirschkind sugere que apesar da relevância de descrevermos os conteúdos substantivos do que se entende por "secular" e "religioso", o ponto central reside em nos determos na relação dinâmica e na tensão produtiva que origina dessa diferenciação. Isto é, ele nos sugere observar a dinâmica de poder relacional como constituinte dos termos e geradora de novas práticas num contínuo processo de autodiferenciação interna.

Mais ainda, na medida em que a identidade de uma prática secular deve-se a uma relação dinâmica particular estabelecida entre essas duas categorias - de que toda prática secular é acompanhada por uma sombra religiosa - então o secular estará sempre sujeito a certa indeterminação e instabilidade. Essa instabilidade, garantida pelo princípio de impossibilidade de eliminar a fronteira entre secular e religioso, não é uma limitação do poder secular, mas a condição de seu exercício (2011, p. 643).

A hipótese que vamos sugerir nas conclusões detém-se justamente sobre esse aspecto: uma dinâmica relacional entre exercícios de poder diferenciados e diferenciantes que se articula em níveis. Para tanto, lançaremos mão do conceito de cismogênese de Gregory Bateson $(1935 ; 2008)$ e visaremos a desenvolver a interpretação que Duarte (2009) fez do contexto brasileiro por meio do mesmo conceito. 
IMAGENS (DE) EVANGÉLICAS

Figura 1

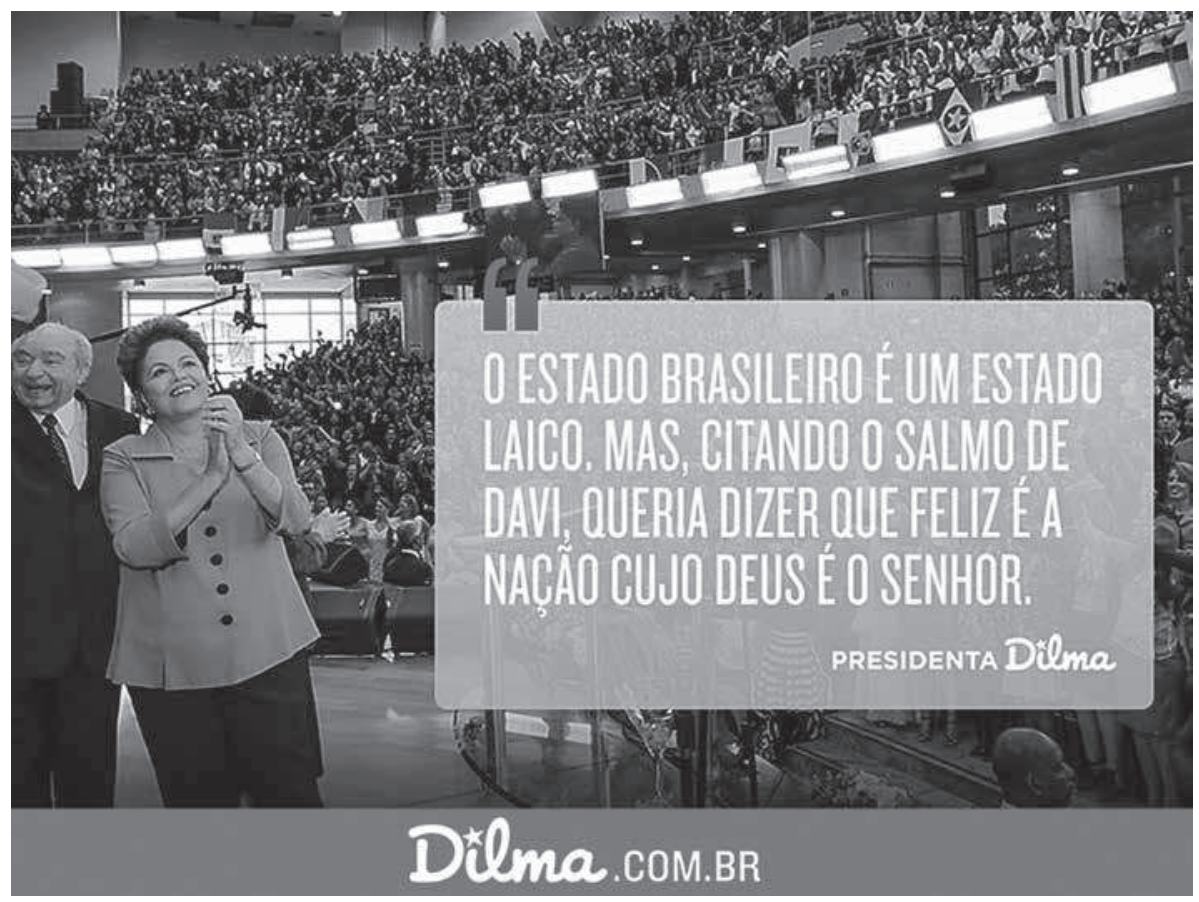

Disponível em: <https://pt-br.faceboook.com/SiteDilmaRousseff>. 
Figura 2

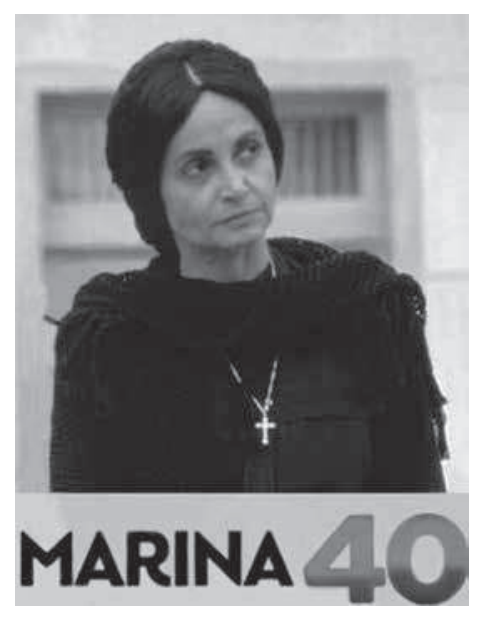

As duas imagens anteriormente apresentadas foram utilizadas durante a disputa eleitoral. A primeira delas é parte da campanha oficial de Dilma Rousseff e a traz em um evento da Assembleia de Deus, estampando a frase que foi dita na ocasião: "O Estado brasileiro é um Estado laico. Mas, citando o salmo de Davi, queria dizer que Feliz é a nação cujo Deus é o senhor". A segunda imagem foi divulgada em diversas redes sociais assim que foi confirmada a candidatura de Marina Silva à presidência, após o falecimento de Eduardo Campos. A chamada avisava: "Vazou o santinho de Marina”. A imagem, entretanto, não traz a fotografia da candidata, mas de uma conhecida personagem da novela Tieta, a Perpétua. A personagem é descrita no site da Rede Globo sobre a novela como a caricatura de uma mulher extremamente religiosa e falsa, uma "beata" que "[...] comete todos os pecados capitais, usando a defesa da família como argumento"6.

As diferenças entre as duas imagens são enormes, já que uma é oficial e a outra não, mas o aspecto mais relevante para nossa discussão é que a candidata que enaltece a dimensão religiosa da nação e promove uma

6 Disponível em: <http://memoriaglobo.globo.com/programas/entretenimento/novelas/ tieta/galeria-de-personagens.htm>. Acesso em: 7 jan. 2015.

Debates do NER, Porto Alegre, ano i6, N. 27, P. I73-I98, JAn./Jun. 2015 
conexão a contrapelo de determinados segmentos cristãos com o Estado não é a candidata religiosa. As relações parecem simetricamente invertidas: é a candidata que foi diversas vezes reconhecida como "não crendo" que afirma uma relação positiva entre a nação e o Deus cristão, ao passo que a candidata que é publicamente crente no Deus cristão faz questão de afirmar que o Estado deve se manter separado da Igreja.

Qual teria sido a repercussão caso a frase em questão tivesse sido enunciada por Marina Silva? Ao colocar essa questão, tornamos visível que a frase só pode ser enunciada por ser notório que Dilma Rousseff não é religiosa, o que desloca a veracidade de seu enunciado. Como afirmamos anteriormente, há uma disjunção em jogo, isto é, é preciso observar que há uma distorção performativa. Os correligionários de Dilma possuem o sentido implícito da frase, que não é o que a frase afirma explicitamente. Alguns partidos políticos afirmam uma necessidade de estabelecer laços políticos com os evangélicos, na medida em que eles podem ser capazes de reunir um grande percentual de votos. Essa posição normalmente argumenta que se trata de encarar as coisas como elas são, sem idealismo, numa postura mais próxima da Realpolitik. Nesse caso, e afastando-nos do ponto de vista nativo, poderíamos dizer que este enunciado é cínico.

A mesma construção linguística de "ato de fala de duplo nível" (Safatle, 2008) é encontrada na imagem da Marina-Perpétua. Aqui, não mais o cinismo, mas a ironia é que se manifesta, na medida em que podemos observar a subversão da expectativa: ao invés da imagem de Marina, encontramos o de uma personagem. Essa "incongruência” remete - do ponto de vista do enunciador - a uma verdade oculta, que se torna manifesta no humor: Marina é uma candidata religiosa (talvez falsa como a Perpétua) e essa é a principal caracterização a ser feita a respeito dela. As semelhanças físicas, como o aspecto severo e o cabelo preso, reforçam a identificação e auxiliam na promoção da risada. Conforme afirmamos, assim como no caso do cinismo, a ironia depende do reconhecimento da disjunção entre o que é esperado e o que é mostrado. É o reconhecimento dessa disjunção e sua adesão enquanto motivo de riso que demonstra o senso de comunidade partilhado.

Debates do NER, Porto Alegre, ANo I6, N. 27, P. I73-I98, JAN./Jun. 2015 
É relevante que compreendamos a cronologia dos eventos ligados ao aparecimento da religião na campanha eleitoral. Obviamente a linha do tempo que ofereceremos aqui é uma seleção de fatos, não pretendendo esgotar todos os acontecimentos, mesmo aqueles em que os agentes principais de nossa análise estão envolvidos. Com isso queremos dizer que não iremos nos deter no candidato Pastor Everaldo, do Partido Social Cristão (PSC), nem iremos nos deter na discussão levantada pelos comentários do candidato Levy Fidelix, do Partido Renovador Trabalhista Brasileiro (PRTB), em um dos debates. Ou seja, nossa cronologia está relacionada com a candidata Marina Silva e eventos relacionados a ela. Isso se deve a três razóes centrais: a primeira é a sua preeminência no pleito, considerando sua performance na eleição de 2010 e a expectativa de votos para a de 2014; a segunda é a quantidade de elementos religiosos acionados por diferentes agentes; a terceira é que não estamos perseguindo uma análise dos jogos políticos ou das estratégias eleitorais, mas uma percepção da sensibilidade secular e uma circunscrição é necessária para a compreensão heurística inicial, o que não impede futuras comparações com outros eventos envolvendo outros agentes.

Dito isso, estabelecemos uma linha com sete pontos: 1. Marina vice de Campos; 2. o acidente aéreo e o falecimento de Campos; 3. a profecia da futura presidente; 4. divulgação do Programa de Governo e retrocesso em tópico LGBT; 5. associação e contraposição com Malafaia e Jean Willis; 6. o pertencimento religioso de Marina; 7. e termina com o apoio ao Aécio Neves.

Nas eleições de 2010, Marina conquistara cerca de 20 milhōes de votos, pelo Partido Verde. Ela ficou em terceiro lugar entre os candidatos à presidência, perdendo para Dilma Rousseff, presidente eleita pelo Partido dos Trabalhadores (PT), e para o segundo colocado, José Serra, candidato do Partido da Social Democracia Brasileira (PSDB). Isso a tornou uma forte aliada política.

Debates do NER, Porto Alegre, Ano I6, N. 27, P. I73-I98, JAn./Jun. 2015 
A candidatura de Marina Silva à vice-presidência causou uma grande expectativa no cenário político. Após ver negado pelo Tribunal Superior Eleitoral o registro de seu partido (a Rede Sustentabilidade), parecia que ela não concorreria às eleições de 2014. Entretanto, o Partido Socialista Brasileiro (PSB) a escolheu para ser vice-presidente de seu candidato, Eduardo Campos, ex-governador de Pernambuco. A posição de Marina Silva no PSB sempre foi alvo de estranhamento. Desde sua filiação ao partido, em outubro de 2013, houve inúmeras especulaçóes. Se, por um lado, havia quem acreditasse que ela seria a candidata à presidência pelo $\mathrm{PSB}$, por outro, o seu duplo pertencimento, ao PSB e à Rede Sustentabilidade, causava desconfiança. Ainda assim, a estratégia do PSB parecia simples, lançar a candidatura de Marina Silva é começar as eleiçôes já com $20 \%$ dos votos do eleitorado brasileiro.

Mesmo que isso significasse ser coadjuvante das eleições, o apoio de Marina parecia ser sustentado pela ambição de ruptura com a polarização PT-PSDB que compõe, desde 1994, o cenário político brasileiro das disputas presidenciais. Posteriormente, ela assumiria a identidade de ser uma terceira via para a política brasileira, aliada a discursos de renovação política.

Porém, o jogo político altera-se radicalmente quando o candidato Eduardo Campos sofre um acidente aéreo que ceifa sua vida. $\mathrm{Na}$ ocasião, ao pronunciar-se sobre a morte do companheiro de chapa, Marina Silva afirma: "Sinto o senso de responsabilidade e compromisso que a perda de Eduardo impõe", e diz que foi "providência divina" não ter embarcado naquele avião ${ }^{7}$. É possível marcar aqui o início da presença da religião no debate político. A repercussão dessa frase foi imediata.

Rodrigo Constantino, colunista da revista $\mathrm{Veja}^{8}$, afirma "ser um tanto cruel" a atitude de Marina Silva de creditar a Deus sua salvação, dando a entender que ela, ao contrário dos acidentados, tinha ainda um "chamado"

7 Disponível em: <http://politica.estadao.com.br/noticias/geral,marina-diz-que-naoembarcou-por-providencia-divina,1544986>. Acesso em: 16 ago. 2014.

8 Disponível em: <http://veja.abril.com.br/blog/rodrigo-constantino/democracia/providenciadivina/>. Acesso em: 17 ago. 2014.

Debates do NER, Porto Alegre, Ano i6, N. 27, P. I73-I98, JAN./Jun. 2015 
a ser cumprido por aqui. Tal postura, segundo o colunista, apenas fortalece a já assumida, por Marina Silva, “[...] postura messiânica, de salvadora da Pátria, de quem conversa diretamente com Deus e segue seu 'chamado' para mudar o país".

A morte do candidato Eduardo Campos causou uma grande comoção nacional e colocou seu partido numa difícil posição. Àquela altura, não parecia existir nome forte o suficiente para substituir a candidatura de Campos, e apostar em Marina Silva era uma incógnita, devido à sua pouca identificação partidária, uma vez que sua presença no partido era majoritariamente sustentada pelo apoio de Eduardo Campos. Mas, afinal, Marina Silva foi indicada como sucessora do falecido, modificando a estratégia de seus adversários nas eleições presidenciais, o senador Aécio Neves (PSDB) e a presidenta Dilma Rousseff (PT).

Parte do humor que está situado claramente sob a teoria da incongruência é o promovido pelo Sensacionalista, um jornal "isento de verdade". O próprio slogan já é uma piada, na medida em que ele joga com um duplo sentido: ele seria o único verdadeiramente isento para dizer a verdade ou seria aquele que não está dizendo a verdade? Todo o conteúdo é feito com base em notícias verdadeiras, distorcendo-as. Assim é que duas "notícias" deles serão utilizadas em nossa discussão. A primeira é a que se segue, sob a manchete "Marina fundará dissidência evangélica em que Jesus é Eduardo Campos".

Marina Silva, visando juntar política e religião, achou por bem unir seus dois maiores prazeres e fundar a "Igreja Eduardo Campos É O Poder". A Igreja promete ser seu maior curral eleitoral para garantir a fundação do seu novo partido Rede.

Segundo Marina, não significa que Eduardo Campos seja Jesus, na verdade, Jesus é Jesus, porém já que ele precisa ser representado por alguma imagem, será usada a de Eduardo Campos e seu nome readequado ao nome do candidato.

9 Disponível em: < http://sensacionalista.com.br/2014/09/01/marina-fundara-dissidenciaevangelica-em-que-jesus-e-eduardo-campos/>. Acesso em: 19 nov. 2014.

Debates do NER, Porto Alegre, Ano i6, N. 27, P. I73-I98, JAn./Jun. 2015 
A fundação da Igreja poderá ocorrer ainda este ano se Marina não voltar atrás. Disponível em: <http://sensacionalista.com.br/2014/09/01/marinafundara-dissidencia-evangelica-em-que-jesus-e-eduardo-campos/>. Acesso em: 19 nov. 2014).

A notícia traz já de imediato que a candidata une política e religião, sugerindo ser claramente possível distingui-las e evidenciar a percepção de que elas deveriam ser mantidas em separado. Porém, a associação de ideias permite dizer que fundar um partido e fundar uma nova igreja evangélica são atividades bastante semelhantes. A piada prossegue ao jogar com um aspecto da realidade: após a morte trágica de Eduardo Campos, a comoção em Pernambuco foi tamanha que algumas pessoas especularam sobre a criação de uma devoção. Por fim, a piada mais recorrente de todas conclui a matéria.

A cobertura das eleições de 2014, realizada pelo jornal Estado de São Paulo $^{10}$, afirma que o comitê de reeleição da presidenta Rousseff passou a ter como estratégia atribuir à Marina Silva os rótulos de "radical", "conservadora" e "fundamentalista", investindo contra seu pertencimento religioso" ${ }^{11}$. Ainda que não seja nossa proposta discutir as estratégias da disputa eleitoral, esse dado precisa ser mencionado na medida em que iremos argumentar sobre a construção da imagem de evangélica realizada, bem como as associações que sustentaram tal posição.

O site do jornal Estado de São Paulo publicou um texto, escrito por José Roberto de Toledo ${ }^{12}$, em que o autor diz que a entrada de Marina Silva na corrida presidencial representa uma ameaça substantiva aos dois outros

${ }^{10}$ Disponível em: <http://politica.estadao.com.br/noticias/eleicoes,petistas-e-tucanoselegem-marina-como-alvo-para-tentar-retomar-polarizacao,1545902>. Acesso em: 18 ago. 2014.

${ }^{11}$ Marina Silva se diz evangélica, fiel da Igreja Bíblica da Graça, desde que se recuperou de uma contaminação por mercúrio. Disponível em: <http://www.terra.com.br/istoegente/ 54/reportagem/rep_senadora.htm>. Acesso em: 22 ago. 2014.

12 Disponível em: <http://blogs.estadao.com.br/vox-publica/2014/08/18/os-tres-ismos-demarina/>. Acesso em: 18 ago. 2014.

Debates do NER, Porto Alegre, ANo I6, N. 27, P. I73-I98, JAN./Jun. 2015 
candidatos. Aécio Neves passa a correr o risco de não ir para o segundo turno das eleições, enquanto a presidente Dilma Rousseff poderá não se reeleger. Toledo também cita as características das intenções de votos que a pesquisa do Datafolha creditou à candidata. Para ele, o eleitorado de Marina divide-se em dois: os jovens com escolaridade acima da média que estão descontentes com a tradicional estrutura política, e eleitores religiosos (em sua maioria mulheres evangélicas - retornaremos a esta informação posteriormente).

Um dos argumentos que estamos procurando sugerir é o de que o humor permite perceber fronteiras na medida em que percebemos quem ri e de quem se ri, bem como ao identificar os elementos promotores da risada. Outras características que são associadas a essas fronteiras incluem a dificuldade de tradução e o humor ofensivo, "reacionário" (Critchley, 2002, p. 11-12):

A maioria do humor [...] visa, simplesmente, reforçar o consenso e não procura de maneira alguma criticar a ordem estabelecida ou mudar a situação, mas jogar com as hierarquias sociais existentes [...]. Uma grande parte do humor visa confirmar o status quo seja ao denegrir um setor da sociedade, como no humor sexista, ou por meio da risada sobre uma suposta estupidez de um estrangeiro ao grupo [social outsider].

A percepção do humor como ofensivo (ou não ofensivo) depende, entretanto, da posição do observador. É justamente aí que reside a possibilidade de delimitação de fronteiras sociais e de comunidades morais.

A continuidade da imagética de Marina Silva como a personagem Perpétua pode ser vista em outro desenho veiculado durante as eleiçôes. Nele, Marina aparece de preto, com o cabelo preso e semblante severo. Os três momentos da imagem mostra a sua imposição individual sobre o partido político que a abrigou como vice, junto ao qual ela não possui uma trajetória. Essa imposição não se dá por meio de um programa de governo, ainda que ela segure um livro em suas mãos, sem título ou autor visível. A sugestão é de que se trata de uma Bíblia e que por meio dela a candidata transformaria o partido político em uma manifestação religiosa - a pomba

Debates do NER, Porto Alegre, Ano I6, N. 27, P. I73-I98, JAN./Jun. 2015 
do logo virando a imagem do Espírito Santo. O riso no canto da boca de Marina no terceiro momento revelaria uma satisfação com a transformação, deixando claro que é essa a sua disposição real, oculta por trás de preocupaçóes mais seculares, como o meio ambiente.

Figura 3

1
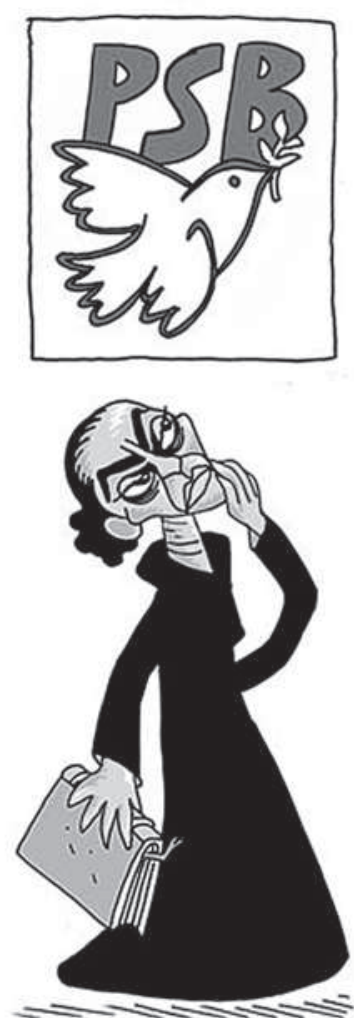

Disponível em: <http://atarde.uol.com.br/charges/simanca-marina-e-o-psb>.

O pertencimento religioso de Marina e o número de religiosos em seu eleitorado com certeza influenciaram a disseminação de um vídeo na internet. No vídeo, o ministro da "Touch of Fire", Bob Hazlett, durante a 
Conferência de Dunamis ${ }^{13}$ de 2011 - um encontro de jovens evangélicos - profetizou a respeito do cenário político brasileiro:

Deus disse que vai mudar a estrutura política desta nação, pois o inimigo já tem dito que controla as casas do Poder, a presidência, mas eu escuto nosso Senhor dizer 'Eu levanto os reis, e eu também os derrubo' [...]. ${ }^{14}$

O pastor afirma que lhe foi revelado que haveria um homem por trás de uma mulher, um homem que a manipula segundo sua vontade, "[...] e ele estava puxando as cordas de uma mulher na liderança do Estado, e ela era sua marionete, pois ele dizia 'ela vai fazer aquilo que eu mandá-la fazer'[...]", mas que Ele a libertaria:

E eu escuto o Senhor dizer que nos próximos dois anos Ele começará a levantar mulheres no Poder desta nação e colocará uma mulher com o Espírito d'Ele nela e ela se ajoelhará perante a Ele assim como Ester se ajoelhava, pois Ele removerá o espírito de Mordecai, que tem tentado controlar as mulheres desta nação, e Ele levantará uma mulher segundo Seu coração, e Ele abalará a nação, levando-a para uma temporada de prosperidade mesmo enquanto outros países enfrentarem crises. (Disponível em: <http://www.idunamis. org/dunamis/movimento-dunamis/quem-somos/>. Acesso em: 8 out. 2014.)

O pertencimento religioso de Marina Silva não só era colocado em cena por seus adversários, como também pelos próprios religiosos que cobravam dela decisões religiosas. A cobrança em relação ao pertencimento religioso

${ }^{13}$ Conferência de Dunamis - "Dunamis é um movimento cristão que instiga e equipa universitários e jovens profissionais a um estilo de vida de avivamento e reforma dentro das esferas da sociedade*, causando transformação onde atuarem”. Disponível em: $<$ http://www.idunamis.org/dunamis/movimento-dunamis/quem-somos/>. Acesso em: 8 out. 2014.

${ }^{14}$ Fonte da transcrição: <http://noticias.gospelmais.com.br/profecia-deus-levantara-mulhergovernar-pais-70512.html>. Vídeo: <https:/www.youtube.com/watch?v=jQ0O1rjKFDA\#t=83>. Acesso em: 19 ago. 2014.

Debates do NER, Porto Alegre, Ano i6, N. 27, P. I73-I98, JAn./Jun. 2015 
de Marina Silva fica mais evidente quando olhamos para o tópico LGBT do seu programa de governo, e para como ele sofreu alteraçôes durante as eleiçôes. Seu programa de governo dizia: "[...] uma sociedade sexista, heteronormativa e excludente em relação às diferenças", "os direitos humanos e a dignidade das pessoas são constantemente violados e guiados, sobretudo, pela cultura hegemônica de grupos majoritários (brancos, homens etc)", e "precisamos superar o fundamentalismo incrustado no Legislativo e nos diversos aparelhos estatais, que condenam o processo de reconhecimento dos direitos LGBT e interferem nele".

E passou a dizer: "[...] vivemos em uma sociedade que tem muita dificuldade de lidar com as diferenças de visão de mundo, de forma de viver e de escolhas feitas em cada área da vida", e "democracia só avança se superar a forma tradicional de supremacia da maioria sobre a minoria e passar a buscar que todos tenham formas dignas de se expressar e ter atendidos seus interesses".

A coordenação justifica as mudanças como "falha processual na editoração" que não "retrata com fidelidade os resultados do processo de discussão sobre o tema durante as etapas de formulação do plano de governo" 15 . O movimento LGBT não ficou contente com a alteração, e o ativista e também deputado do Rio de Janeiro, Jean Wyllys, publicou diversas vezes nas redes sociais que a candidata havia mentido e brincado com a esperança de inúmeras pessoas ${ }^{16}$. E passaram a acusar Silva de obedecer a pressão de setores conservadores e evangélicos, como a de Silas Malafaia, que antes da alteração havia publicado em sua rede social que "o programa de governo de Marina Silva é uma defesa vergonhosa da agenda gay" ${ }^{17}$. Leonardo Boff,

${ }^{15}$ Disponível em: <http://www1.folha.uol.com.br/poder/2014/08/1508539-campanha-demarina-elimina-trechos-de-capitulo-lgbt-do-programa.shtml>. Acesso em: 30 ago. 2014.

16 Disponível em: <http://www.brasil247.com/pt/247/brasil/151849/De-Jean-Wyllys-a -Marina-voc\%C3\%AA-mentiu-a-todos-n\%C3\%B3s.htm>. Acesso em: 30 ago. 2014.

17 Disponível em: <http://brasil.elpais.com/brasil/2014/08/30/politica/1409428082_344003. html>. Acesso em: 30 ago. 2014.

Debates do NER, Porto Alegre, Ano i6, N. 27, P. I73-I98, JAN./Jun. 2015 
católico, militante da teologia da libertação, escreveu uma matéria para o Portal Fórum, endossando a relação entre a mudança do tópico LGBT do programa de governo da candidata do PSB à frase de Malafaia ${ }^{18}$.

Aqui o debate parece ganhar em pluralidade de atores, mas argumentaremos que pode ser melhor compreendido como uma polarização entre esses dois coletivos (o movimento LGBT e a bancada evangélica), numa cismogênese simétrica (Bateson, 1935; 2008) ${ }^{19}$; e que, e este é um aspecto importante que desejamos salientar, a posição de Marina nessa polaridade deve-se a um jogo de associações que revela menos sobre a candidata do que certas sensibilidades seculares da política brasileira. Ela aparece como um suporte para a expressão do que é e do que esperar de uma mulher evangélica como representante política.

É bastante comum que a crítica secular à religião seja feita por uma desqualificação de seus interesses explícitos, visando a desvelar um interesse escuso real. Ainda que essa possa ser a crítica feita à candidata, nosso interesse é observar outro movimento: não o de associação com personagens fictícios, mas com os reais - como o pastor Silas Malafaia.

Uma charge bastante divulgada (de autoria do Laerte) é a que representa a candidata como uma criança. São três os aspectos que permitem essa compreensão. $\mathrm{O}$ primeiro é o tamanho dela em relação à poltrona (com os pés sem tocar o chão), o segundo é o uso de "Tio" para se referir a Silas Malafaia, o terceiro é que ela aparenta estar falando com amigos com os quais irá "brincar". Essa imagem elucida a percepção de que

${ }^{18}$ Disponível em: <http://www.revistaforum.com.br/blog/2014/09/malafaia-fala-marina -obedece-pois-ve-nisso-vontade-de-deus-diz-leonardoboff/04/Setembro/2014>. Acesso em: 30 ago. 2014.

${ }^{19}$ A expectativa de parte do eleitorado é de que essa divisão correspondesse à polarização esquerda versus direita. Porém, se entendermos que a polarização federal entre PT e PSDB seria representativa desses ideais, tal sobreposição não se realiza. Os dois partidos flertam e jogam com o apoio da bancada evangélica e pouco avançam no apoio de bandeiras do movimento LGBT, como fica evidente nas falas de Jean Willys (PSOL). Voltaremos à articulação da candidata Dilma com os setores na conclusão.

Debates do NER, Porto Alegre, Ano i6, N. 27, P. I73-I98, JAn./Jun. 2015 
Marina não é vista como uma adulta capaz de tomar suas próprias decisões e de levar a sério as suas atividades. $\mathrm{Na}$ medida em que isso é dito após o retrocesso do Programa de Governo e após as críticas feitas pelo pastor, a associação entre Marina e Malafaia é feita de maneira inequívoca. Mas não por Marina.

Figura 4

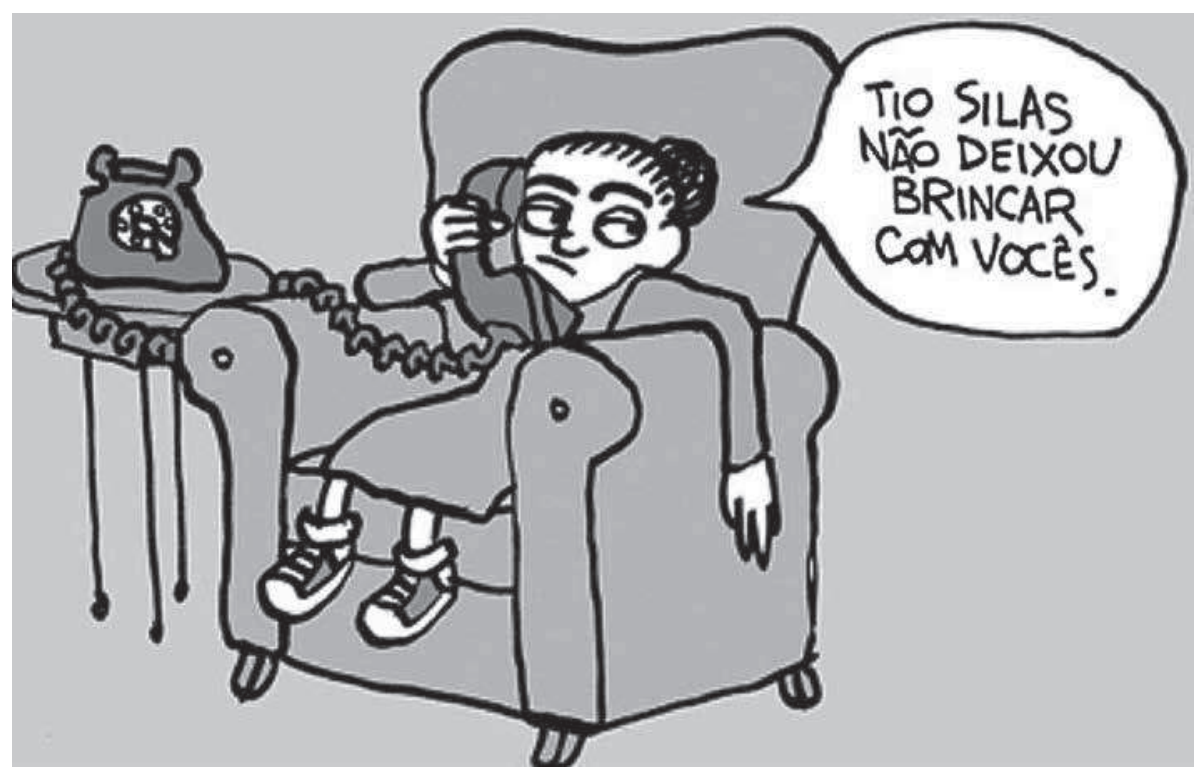

Fonte: Autoria do cartunista Laerte, veiculada primeiramente no jornal Folha de São Paulo, mas coletada de sua divulgação online no Facebook. 2 set. 2014.

Um dos argumentos que estamos perseguindo aqui é o de que Marina não realizou a profecia do pastor Bob Hazlett. Não apenas por não ter se tornado presidente da República, mas, sobretudo, por ser apresentada como infantil e submetida às ordens de um homem. Se anteriormente ela aparecia como vice de Eduardo Campos, no presente momento, ela tem sua agência e capacidade de decisão novamente negada. Ela continuaria sendo vista como a marionete de um homem que a controla. Essa disputa pela posição de Marina é sintomática de um enfrentamento dos coletivos. 


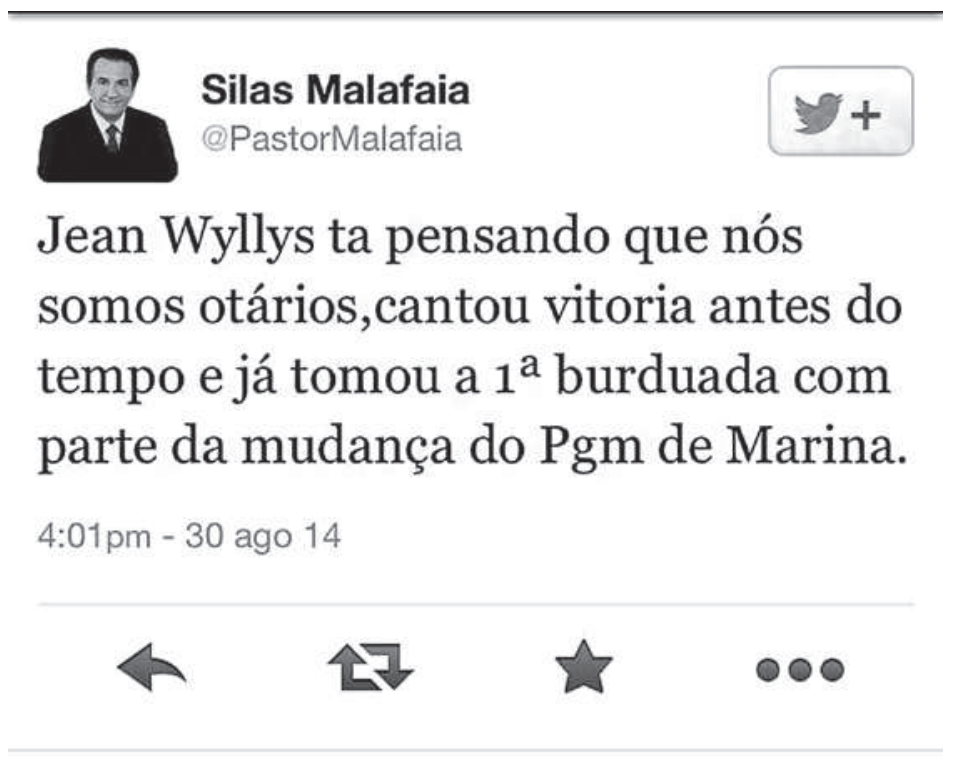

Fonte: <https://twitter.com/pastormalafaia >.

A temática da religião ganhou mais um impulso quando a mídia publicou que Marina consultava a Bíblia em momentos de difícil decisão ${ }^{20}$. Marcelo Hailer escreveu para o Portal Fórum um texto intitulado Marina Silva entre a Bíblia e a Constituiçãa $o^{21}$, e questionou se a candidata iria legislar segundo o livro sagrado ou a constituição. Ela se defendeu dizendo que estavam tentando taxá-la de fundamentalista: "Uma pessoa que crê tem na bíblia uma referência, assim como tem uma referência a arte, a literatura. Às vezes as pessoas podem ter um insight (ideia) assistindo filme"22.

${ }^{20}$ Disponível em: <http://www1.folha.uol.com.br/poder/2014/09/1508909-marinacostuma-recorrer-a-versiculos-da-biblia-para-tomar-decisoes.shtml>. Acesso em: 1 set. 2014.

${ }^{21}$ Disponível em: <http://www.revistaforum.com.br/blog/2014/08/marina-silva-entrebiblia-e-constituicao/>. Acesso em: 18 ago. 2014.

22 Disponível em: <https://www.youtube.com/watch?v=yoHD6htXgdA>. Entrevista ao Jornal da Globo, em 9 de setembro de 2014. Acesso em: 9 set. 2014.

Debates do NER, Porto Alegre, Ano i6, N. 27, P. I73-I98, JAn./Jun. 2015 
Por fim, após o término do primeiro turno e com a disputa encaminhando-se para uma renovada polarização entre PT e PSDB, Marina Silva escolhe o candidato do PSDB como aliado. Aécio Neves comemora: "Com a benção da Nossa Senhora Aparecida, hoje é um dia glorioso para nossa campanha. Recebo com muita honra e responsabilidade o apoio de Marina Silva. A partir de agora somos um só corpo, um só projeto”. Essa afirmação de Aécio, marcada pela menção a Nossa Senhora, é definitivamente católica e não "evangélica". Ao final retomaremos esse aspecto para questionar as razões para isso não ser tomado como um problema nem como uma intromissão da religião na política.

\section{CONSIDERAÇÕES FINAIS}

Uma das pretensões deste artigo foi o de trazer para a análise uma maior variedade de pontos de vista sobre o tema religião e política. Consideramos que não é possível seguirmos discutindo a questão sem levarmos em consideração as diferentes posições que estão não somente articuladas como estão, sobretudo, em uma tensão dinâmica. Em suma, consideramos ser necessário pluralizar as perspectivas e julgamos ser essa uma das tarefas do antropólogo.

Para alcançar nosso objetivo, procuramos avançar na compreensão de uma sensibilidade secular a respeito da presença da religião na política brasileira. O caso da candidata Marina Silva foi importante para que pudéssemos observar quais as noções que são mobilizadas para descrever uma mulher evangélica e, mais ainda, na comparação com uma mulher que não é filiada a nenhuma igreja nem apresenta um histórico pessoal de fé, a presidente Dilma Rousseff. Assim, vimos que a mensagem de campanha de Dilma citada anteriormente não causou repercussão na sensibilidade secular para além de alguns poucos setores mais à esquerda. $\mathrm{O}$ argumento frequentemente apresentado de que o jogo político precisa ser encarado sem idealismo, por meio de alianças e conquista de maiorias (Nobre, 2013) já está suficientemente estabelecido para silenciar maiores discussões. 
Entretanto, isso ainda rende boas piadas. O “jornal” Sensacionalista trouxe como manchete de uma de suas notícias "Dilma pede fim da corrupção ao lado de Collor (pode rir, essa é a piada)". A mensagem entre parênteses é a única parte que torna a manchete "isenta de verdade", pois a presidente Dilma tinha, de fato, aparecido em um palanque com o Collor para pedir o fim da corrupção. Após dar a notícia, o texto termina com "O texto acima é verdadeiro. Não julgamos necessário fazer qualquer piada”. O jogo de incongruência chega, aqui, no seu limite. A incongruência deixa de ser da enunciação e passaria a ser da própria vida social. Esse é o caso também de outra notícia do Sensacionalista: "Para agradar eleitorado evangélico, Governo cria o bolsa-dízimo". Aqui, o lastro de realidade que motivou a matéria é a contraofensiva da campanha de Dilma para conquistar a bancada evangélica, para a qual acenou com a possibilidade de aprovação da Lei Geral das Religiōes.

Em todas essas ocasióes, sentimos ecoar a frase de Mary Douglas: "Minha hipótese é a de que uma piada acontece e é permitida quando ela oferece um padrão simbólico para um padrão social que está ocorrendo ao mesmo tempo" (Douglas, 1975, p. 98). Talvez o padrão simbólico da ironia, como um ato de fala de duplo nível, seja o mais adequado para jogar com o formato do cinismo, promovendo o humor. No entanto, isso se dá para certas comunidades morais que compartilham de uma sensibilidade específica secular, segundo a qual a religião deveria ficar afastada da política.

Assim, ainda que a campanha de Dilma tenha feito alianças com setores evangélicos, em momento algum isso foi visto como uma intromissão da religião na política de mesma natureza que a de Marina. Nosso argumento é o de que a sensibilidade secular coloca a ênfase mais na crença do que nas práticas. Por não ser pessoalmente religiosa, Dilma não é vista como tão nociva à laicidade do Estado, ao passo que Marina é altamente perigosa, mesmo não acenando para os setores evangélicos como fez a presidente.

De fato, não foi Marina quem procurou a associação com os evangélicos, mas alguns, como Malafaia, que procuraram se associar a ela. Ao não reconhecer essa ação deliberada de Marina, bem como ao tentar fazer

Debates do NER, Porto Alegre, Ano I6, N. 27, P. I73-I98, JAN./Jun. 2015 
da dimensão privada a explicação da persona pública, fica evidente que a discussão dizia respeito menos à Marina do que a uma dinâmica englobante.

Diversos autores (Taylor, 2007; Keane, 2013) já pontuaram que a posição secular é pautada por uma narrativa moral do progresso, da emancipação humana e a ela corresponde o avanço de Direitos Humanos que eram negados no passado. Isso é ainda mais evidente quando se discute a posição da mulher na sociedade. Os países muçulmanos, por exemplo, são chamados de "atrasados" 23 e as mulheres muçulmanas nos países europeus são vistas como necessariamente oprimidas (Göle, 1997). Nesse cenário, a mulher religiosa ainda é vista, pela posição secular, como submissa ou ainda como a marionete de outrem - e essa parece ser também a interpretação secular acerca de Marina Silva.

Entretanto, o que nos parece central é a oposição entre dois coletivos no formato que Bateson chamou de cismogênese - e isso é mais visível na tensão entre moralidades dissonantes como a dos movimentos feministas e LGBT e de setores evangélicos. Nossa sugestão aqui, e é preciso pontuar a importância da tese de Duarte (2009), é a de que está ocorrendo não apenas uma cismogênese simétrica entre os dois coletivos, mas que essa cismogênese é articulada com outras cismogêneses complementares. Em outras palavras, vemos um processo de cismogênese complexa em níveis articulados, sendo o nível simétrico o mais imediato e mais perceptível fenomenologicamente. Bateson $(1935 ; 2008)$ definiu a cismogênese simétrica como aquela em que os dois indivíduos ou grupos possuem um comportamento semelhante, isto é, A reage a $\mathrm{B}$ de maneira $\mathrm{X}$ e $\mathrm{B}$ reage a $\mathrm{A}$ da mesma maneira $\mathrm{X}$. É curioso como ambos os coletivos em questão acusam o seu adversário de ser autoritário e tentar impor suas ideias sobre o restante da população. Se os evangélicos são chamados de fanáticos e fundamentalistas, o movimento LGBT recebeu por parte dos primeiros a alcunha de "ditadura gayzista".

${ }^{23}$ Uma central de inteligência, ao analisar as postagens online de mulheres ocidentais que se uniram ao Estado Islâmico, concluíram que a vida delas é similar ao de uma mulher americana nos anos 1950 .

Debates do NER, Porto Alegre, ANo I6, N. 27, P. I73-I98, JAN./Jun. 2015 
Não é o bastante parar nesse nível, pois a relação entre esses coletivos não é simétrica. A cismogênese complementar é aquela em que os grupos estão em posiçôes de poder diferenciadas, como as classes sociais, por exemplo. Aqui, saímos do nível fenomenológico e entramos, em nível crescente, no sociológico e no cosmológico. No nível sociológico, podemos notar que a balança pesa mais para os religiosos, ao menos no caso do Brasil. Ainda que historicamente o Brasil tenha sido construído como uma nação católica, temos atualmente uma população em que mais de $20 \%$ se declara pertencendo a alguma igreja "evangélica" e a maioria ainda é cristã frente a uma pequena percentagem de ateus. Mesmo que empiricamente não exista uma sobreposição entre os militantes LGBT e os ateus, segundo a posição da Associação de Ateus e Agnósticos (ATEA), apenas o movimento LGBT foi capaz de entender o verdadeiro sentido da laicidade (Montero; Dullo, 2014). Como um de nós procurou analisar, a própria percepção da laicidade no Brasil está imbuída da posição católica, já que é no desvio da norma católica estabelecida pela Igreja e para a Igreja que é reconhecida a intromissão da "religião" na "política" (Dullo, 2013).

Porém, parar neste segundo nível ainda é não compreender a complexidade do movimento em curso. O terceiro nível, cosmológico, retorna o peso da balança para o coletivo LGBT. Podemos dizer que vivemos num mundo secular e que são as categorias desse mundo e dessa forma de pensamento que oferecem as condições de possibilidade para que operemos em relação às nossas experiências acerca da temporalidade, do corpo, da realidade.

Ainda é cedo para saber como irá se desenvolver o conflito entre os grupos e se a intolerância irá chegar ao ponto de promover uma ruptura. Talvez o sistema de contrapeso entre os diferentes níveis seja o suficiente para evitar a cisão, talvez não. Parece-nos evidente que a tensão entre os coletivos alimenta a própria fronteira entre secular e religioso, bem como torna evidente como não é possível analisar a presença da religião na política sem que tenhamos nos dedicado a entender as diversas perspectivas e posições envolvidas nos exercícios de poder dessa dinâmica relacional em constante tensão.

Debates do NER, Porto Alegre, Ano I6, N. 27, P. I73-I98, JAN./Jun. 2015 


\section{REFERENCIAS}

ASAD, Talal. A construção da religião como uma categoria antropológica. Cadernos de Campo, São Paulo, n. 19, p. 263-284, 2010.

Formations of the secular: Christianity, Islam, modernity. Stanford: Stanford University Press, 2003.

BATESON, Gregory. Culture contact and schismogenesis. Man, London, v. 35, p. 178-183, 1935.

. Naven: um exame dos problemas sugeridos por um retrato compósito da cultura de uma tribo da Nova Guiné, desenhado a partir de três perspectivas. São Paulo: EDUSP, 2008.

BEM, Daniel F. de; LEISTNER, Rodrigo M. Caminhos Trancados (?): Conflitos e projetos políticos afro-religiosos e o processo eleitoral no Rio Grande do Sul. Debates do NER, Porto Alegre, v. 18, p. 129-148, 2010.

CASANOVA, José. The Secular, Secularizations, Secularisms. In: CALHOUN, Craig; JUERGENSMEYER, Mark; VAN ANTWERPEN, Jonathan (Ed.). Rethinking Secularism. New York: Oxford University Press, 2011.

CRITCHLEY, Simon. On humour. London: Routledge, 2002.

DOUGLAS, Mary. Jokes. In: Implicit Meanings: essays in anthropology. London: Routledge \& Paul, 1975.

DUARTE, Luiz Fernando Dias. Família, Moralidade e Religião: tensões contrastivas contemporâneas à busca de um modelo. In: VELHO, Gilberto C. A.; DUARTE, Luiz F. D. (Org.). Geraçôes, família, sexualidade. Rio de Janeiro: Editora Sete Letras, 2009.

DULLO, Eduardo. Após a (Sociologia/Antropologia da) religião, o Secularismo? Mana, Rio de Janeiro, v. 18, n. 2, p. 379-39, 2012.

Política Secular e intolerância religiosa. In: JORNADAS SOBRE ALTERNATIVAS RELIGIOSAS, XVII., 2013, Porto Alegre. Anais... Porto Alegre: UFRGS, 2013.

Debates do NER, Porto Alegre, ANo I6, N. 27, P. I73-I98, JAN./Jun. 2015 
DUMONT, Louis. O individualismo. Rio de Janeiro: Rocco, 1985.

GÖLE, Nilufer. The forbidden modern: civilization and veiling. Ann Arbor: The University of Michigan Press, 1997.

HIRSCHKIND, Charles. Is there a secular body? Cultural Anthropology, Houston, v. 26, n. 4, p. 633-647, 2011.

KEANE, Webb. Secularism as a moral narrative of modernity. Transit: Europaïsche Revue, n. 43, p. 159-170, 2013.

LUNA, Naara. Aborto no Congresso Nacional: o enfrentamento de atores religiosos e feministas em um Estado laico. Rev. Bras. Ciênc. Polit., Brasília, DF, n. 14, p. 83-109, 2014.

MEIRELLES, Mauro; WEEGE, Adriana; PICOLLOTO, Mariana. Vivendo entre dois mundos: os evangélicos e a política dentro e fora dos templos frente as eleições de 2010. Debates do NER, Porto Alegre, v. 18, p. 111-127, 2010.

MONTERO, Paula; DULLO, Eduardo. Ateísmo no Brasil: da invisibilidade à crença fundamentalista. Novos Estudos CEBRAP, São Paulo, n. 100, p. 57-79, 2014.

NAVARO-YASHIN, Yael. Faces of the State: Secularism and Public Life in Turkey. Princeton: Princeton University Press, 2002.

NOBRE, Marcos. Imobilismo em movimento. Da abertura democrática ao governo Dilma. São Paulo: Companhia das Letras, 2013.

ORO, Ari Pedro; MARIANO, Ricardo. Eleições 2010: Religião e política no Rio Grande do Sul e no Brasil. Debates do NER, Porto Alegre, v. 11, p. 11-38, 2010.

OTERO, Andrea G.; ÁVILA, Cíntia A.; SHOENFELDER, Rosilene dos Santos. Religiōes Afro-Brasileiras: Rivalidade e Fracasso Eleitoral. Debates do NER, Porto Alegre, v. 6, p. 129-148, 2004.

SAFATLE, Vladimir. Cinismo e falência da crítica. São Paulo: Boitempo Editorial, 2008.

Debates do NER, Porto Alegre, Ano I6, N. 27, P. I73-I98, JAn./Jun. 2015 
SALES, Lílian. A controvérsia em torno da liberação da pesquisa com células tronco embrionárias no Brasil: posições e argumentos dos representantes da Igreja Católica. Revista de Antropologia (USP), São Paulo, v. 57, n. 1, p. 179-214, 2014.

STEINMÜLLER, Hans. The State of Irony in China. Critique of Anthropology, v. 31, n. 1, p. 21-42, 2011.

STRATHERN, Marilyn. The limits of auto-anthropology. In: JACKSON, Anthony (Ed.) Anthropology at home. London; New York: Tavistock Publications, 1987.

TADVALD, Marcelo. Eleitos de Deus e pelo povo: Os evangélicos e as Eleições Federais de 2010. Debates do NER, Porto Alegre, v. 11, p. 83-109, 2010.

TAYLOR, Charles. A Secular Age. Cambridge, MA.: Harvard University Press, 2007.

Recebido em: 31/01/2015

Aprovado em: 06/03/2015 